\title{
Enabling Grid-Feeding Converters with a Dissonant-Resonant Controller for Negative-Sequence Voltage Elimination
}

\author{
Manel Velasco, Pau Martí, Antonio Camacho, Juan M. Rey, Jaume Miret, Member, IEEE, and Miguel Castilla
}

\begin{abstract}
The mitigation of the adverse effects of voltage unbalance in equipment and power quality can be performed by the power electronic converters that interface distributed generators to the grid. Inspired in a resonant controller, this paper presents a dissonant-resonant controller for negative-sequence voltage elimination for a grid-feeding converter connected to the grid. The controller eliminates the negative-sequence voltage at the converter output with a regulable precision, it does not require knowing the grid impedance for successful operation, and it can be a good candidate for parallel operation because it operates not like an integrator, but like an "untuned" integrator. Using the stationary $\alpha \beta$ frame, a closed-loop model is developed in a complex space vector built from the complexification of the stationary components. This allows extracting stability conditions for safe closed-loop operation as well as deriving design guidelines for the controller parameters. Numerical and experimental results show the ability of the proposed controller to meet its design goals, thus corroborating the theoretical approach.
\end{abstract}

Index Terms-Grid-feeding converter, $\alpha \beta$ components, negative-sequence, resonant controller

\section{INTRODUCTION}

One of the most common phenomena in power systems is voltage unbalance. Its elimination is motivated by the adverse effects on equipment and power quality, such as electrical machine overheating, transformer overloading, capacity limitation of power electronics, more losses and less stability of power system, and negative impacts on induction motors and adjustable speed drives [1], [2]. The voltage unbalanced concerns trigger also new regulations in grid codes. Although the definition and regulation of voltage unbalance differs among standardization organizations and local regulators, for example, the standard EN 50160 indicates that the voltage unbalance factor must be less than $2 \%$ for low and medium voltage systems [3].

Therefore, control techniques to compensate the unbalance must be developed. Electronic converters interfacing dis-

M. Velasco, P. Martí and A. Camacho are with the Automatic Control Department, Technical University of Catalonia, Pau Gargallo 5, 08028 Barcelona, Spain, email: \{manel.velasco,pau.marti,antonio.camacho.santiago\}@upc.edu

J.M. Rey is with Escuela de Ingenierías Eléctrica, Electrónica y de Telecomunicaciones (E3T), Universidad Industrial de Santander (UIS), 680002 Bucaramanga, Colombia, and with the Electronic Engineering Department, Technical University of Catalonia, Av. Victor Balaguer s/n, 08800 Vilanova i la Geltrú, Spain, email:juanmrey@uis.edu.co

J. Miret and M. Castilla are with the Electronic Engineering Department, Technical University of Catalonia, Av. Victor Balaguer s/n, 08800 Vilanova i la Geltrú, Spain, email:\{jaume.miret,miquel.castilla\}@upc.edu

This work was supported by the Ministry of Science, Innovation and Universities of Spain and by the European Regional Development Fund under project RTI2018-100732-B-C22. tributed generation units (DGs) in grid-feeding, grid-forming, or grid-supporting configurations [4] can be considered a promising solution in front of other strategies that require installing additional equipments such as series or shunt active power filter, series-parallel compensators, static synchronous compensators, and energy storage units [5]-[7].

Research regarding grid-connected converters under unbalanced grid voltage has been largely treated, see e.g. [8]-[28]. Most of the control proposals serve diverse control objectives (mitigation of the unbalance, voltage-ride through, mitigation of voltage fluctuations, elimination of harmonics, elimination of dc link current ripples, etc) while considering different type of grid impedances. However none of them is devoted only at eliminating the negative-sequence voltage that the grid unbalance generates with independence of the specific grid impedance.

Limiting the scope to grid-feeding converters, this paper presents a control strategy that targets negative-sequence voltage elimination at the inverter output where a local load is connected. The voltage unbalance is assumed to be generated by the main grid. This assumption permits focusing only on the negative-sequence controller because both the negativesequence controller and the positive-sequence controller (in charge of delivering the active power to the grid, among other tasks) are decoupled in terms of steady-state dynamics. The development of an appropriate control algorithm is challenging since existing control algorithms may not be directly applicable if parallelization is desired. Note that these power converters already operate in parallel with other grid-feeding power converters in grid-connected mode.

While the proportional-integral (PI) controller guarantees zero steady-state error for DC references, for AC references unavoidable steady-state amplitude and phase errors occur because it does not comply with the internal model principle [29]. Complementary, resonant (R) controllers [30] become a promising alternative because they have been developed upon the internal model principle [31], and they have been applied in many forms and scenarios in power generation systems [32]-[34].

Motivated by these advantages, $\mathrm{R}$ controllers are chosen as a baseline control approach to eliminate the negative-sequence voltage. Moreover, they are generalized into a new form called dissonant-resonant (DR) controllers in order to provide a richer set of performance features. The DR controller is defined in the $\alpha \beta$ stationary reference frame, which implies that grid voltages are transformed to the $\alpha \beta$ components and then, by 


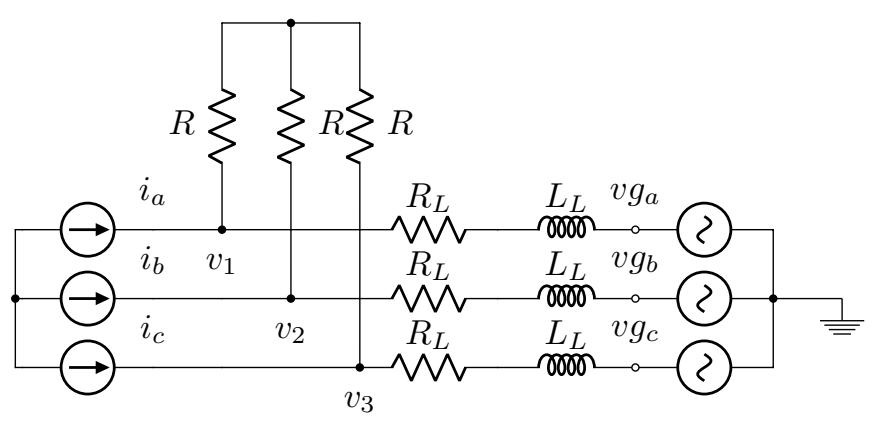

Fig. 1. Scheme of the grid-feeding converter (modeled as a three-phase current source) with a local load and connected to the grid through an RL line.

means of a sequence extractor, into symmetric sequences for negative-sequence voltage elimination. See [35]-[38] for the foundations, review and implemetation details of sequence extractors. This paper uses the second order generalized integrator (SOGI) [36], [37] as a sequence extractor.

The constructive idea behind the DR controller is to obtain an untuned integrator through a generalization of a $\mathrm{R}$ controller. The untuned feature is included to avoid undesirable properties that otherwise may appear when multiple integrators are operated in parallel, such as destabilizing effects or reaching undesirable equilibria [39], [40]. Intuitively, in the Laplace domain, an untuned integral controller for DC references could be understood as a low-pass filter with an adjustable pole that can be made as close to zero as desired. For AC references, the generalization of the $\mathrm{R}$ controller is achieved by adding an additional frequency to the natural frequency to alter the rotation frequency, creating a dissonant effect. The design of the additional frequency permits increasing the set of desired transient dynamics for the closed-loop system with respect to those that can be achieved by a standard $\mathrm{R}$ controller. The paper also presents the stability analysis and controller design guidelines for the DR controller. A closedloop model is presented in the $\alpha \beta$ frame using a complex space vector built from the complexification [41] of the $\alpha \beta$ negative-sequence components. The presented DR controller has been experimentally tested in a laboratory set-up and its performance results corroborate its effectiveness.

The rest of this paper is structured as follows. Section II presents the problem to be solved. Section III presents the controller. Section IV presents the stability analysis and provides controller design guidelines. Section V summarizes the experimental results and Section VI concludes the paper.

\section{PRoblem Definition}

\section{A. Plant Model}

The considered three-phase plant is illustrated in Fig. 1. Without loss of generality, it is assumed that the unbalance occurs at the grid side, and $R$ is a sensitive local load that requires balanced voltages. Therefore, the output voltages $v_{1}$, $v_{2}$ and $v_{3}$ of the grid-feeding converter must be balanced.

By using the modified nodal analysis, the plant can be compactly described by

$$
\vec{v}_{1,2,3}=\mathbf{G}(s) \vec{i}_{a, b, c}+\mathbf{W}(s) \overrightarrow{v g}_{a, b, c}
$$

whose detail is given by

$$
\begin{aligned}
\left(\begin{array}{l}
v_{1}(s) \\
v_{2}(s) \\
v_{3}(s)
\end{array}\right) & =\left(\begin{array}{lll}
G_{11}(s) & G_{12}(s) & G_{13}(s) \\
G_{21}(s) & G_{22}(s) & G_{23}(s) \\
G_{31}(s) & G_{32}(s) & G_{33}(s)
\end{array}\right)\left(\begin{array}{c}
i_{a}(s) \\
i_{b}(s) \\
i_{c}(s)
\end{array}\right) \\
& +\left(\begin{array}{lll}
W_{11}(s) & W_{12}(s) & W_{13}(s) \\
W_{21}(s) & W_{22}(s) & W_{23}(s) \\
W_{31}(s) & W_{32}(s) & W_{33}(s)
\end{array}\right)\left(\begin{array}{c}
v g_{a}(s) \\
v g_{b}(s) \\
v g_{c}(s)
\end{array}\right) .
\end{aligned}
$$

Matrices $\mathbf{G}(s)$ and $\mathbf{W}(s)$ in (1), where $s$ is the Laplace operator, are symmetric with diagonal and off-diagonal transfer functions, $G_{i i}(s)$ and $G_{i j}(s)$ or $W_{i i}(s)$ and $W_{i j}(s)$, given by

$$
\begin{aligned}
G_{i i}(s) & =\frac{L_{L}{ }^{2} s^{2}+\left(2 L_{L} R_{L}+3 R L_{L}\right) s+R_{L}{ }^{2}+3 R R_{L}}{3 L_{L} s+3 R+3 R_{L}} \\
G_{i j}(s) & =\frac{L_{L}{ }^{2} s^{2}+2 L_{L} R_{L} s+R_{L}{ }^{2}}{3 L_{L} s+3 R+3 R_{L}} \\
W_{i i}(s) & =\frac{L_{L} s+R_{L}+3 R}{3 L_{L} s+3 R+3 R_{L}} \\
W_{i j}(s) & =\frac{L_{L} s+R_{L}}{3 L_{L} s+3 R+3 R_{L}}
\end{aligned}
$$

The grid voltages and currents are transformed into the $\alpha \beta$ frame. This is done by applying the $\alpha \beta$ tranformation

$$
\vec{x}_{a, b, c}=\left(\begin{array}{l}
x_{a} \\
x_{b} \\
x_{c}
\end{array}\right)=\left(\begin{array}{ccc}
1 & 0 & 1 \\
-\frac{1}{2} & \frac{\sqrt{3}}{2} & 1 \\
-\frac{1}{2} & -\frac{\sqrt{3}}{2} & 1
\end{array}\right)\left(\begin{array}{l}
x_{\alpha} \\
x_{\beta} \\
x_{\gamma}
\end{array}\right)=T \vec{x}_{\alpha, \beta, \gamma}
$$

where $x_{i}$ stands for either current or voltage in the given frame. By applying the transformation (7) to the model given in (1), the following plant expression is obtained

$$
\begin{aligned}
\vec{v}_{\alpha, \beta, \gamma} & =T^{-1} \mathbf{G}(s) T \vec{i}_{\alpha, \beta, \gamma}+T^{-1} \mathbf{W}(s) T \overrightarrow{v g}_{\alpha, \beta, \gamma} \\
& =\mathbf{G}_{\alpha, \beta, \gamma}(s) \vec{i}_{\alpha, \beta, \gamma}+\mathbf{W}_{\alpha, \beta, \gamma}(s) \overrightarrow{v g}_{\alpha, \beta, \gamma}
\end{aligned}
$$

whose detail is given by

$$
\begin{aligned}
\left(\begin{array}{c}
v_{\alpha}(s) \\
v_{\beta}(s) \\
v_{\gamma}(s)
\end{array}\right) & =\left(\begin{array}{ccc}
G_{\alpha \alpha}(s) & 0 & 0 \\
0 & G_{\beta \beta}(s) & 0 \\
0 & 0 & G_{\gamma \gamma}(s)
\end{array}\right)\left(\begin{array}{c}
i_{\alpha}(s) \\
i_{\beta}(s) \\
i_{\gamma}(s)
\end{array}\right) \\
& +\left(\begin{array}{ccc}
W_{\alpha \alpha}(s) & 0 & 0 \\
0 & W_{\beta \beta}(s) & 0 \\
0 & 0 & W_{\gamma \gamma}(s)
\end{array}\right)\left(\begin{array}{l}
v g_{\alpha}(s) \\
v g_{\beta}(s) \\
v g_{\gamma}(s)
\end{array}\right)
\end{aligned}
$$

where

$$
\begin{aligned}
& G_{\alpha \alpha}(s)=G_{\beta \beta}(s)=\frac{R L_{L} s+R R_{L}}{L_{L} s+R+R_{L}}, G_{\gamma \gamma}(s)=R_{L}+L_{L} s \\
& W_{\alpha \alpha}(s)=W_{\beta \beta}(s)=\frac{R}{L_{L} s+R+R_{L}}, W_{\gamma \gamma}(s)=1 .
\end{aligned}
$$

It is interesting to observe that the $\alpha \beta$ plant model (8)-(10) is decoupled (diagonal) and each voltage can be controlled individually. At this point, the modeling effort makes use of the property that complex numbers $\mathbb{C}$ can be represented by particular real matrices in $\mathbb{R}^{2 x 2}$ [41] as follows

$$
a+j b \leftrightarrow\left(\begin{array}{cc}
a & -b \\
b & a
\end{array}\right)
$$

where $a, b \in \mathbb{R}$ and $j=\sqrt{-1}$, and under which addition and multiplication of complex numbers and matrices correspond to 


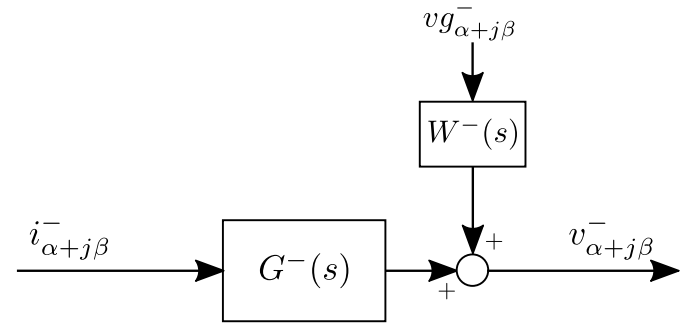

Fig. 2. Open-loop system.

each other. Then, looking at the plant model (8)-(10), it can be observed that the first two diagonal elements of $\mathbf{G}_{\alpha, \beta, \gamma}$, $G_{\alpha \alpha}(s)$ and $G_{\beta \beta}(s)$, are equal, and that the corresponding offdiagonal elements $G_{\alpha \beta}$ and $G_{\beta \alpha}$ are equal and with opposite sign. Hence, the $\alpha \beta 2 \times 2$ subsystem of $\mathbf{G}_{\alpha, \beta, \gamma}$ satisfies the complexification property (11). A similar observation can be made for the $\alpha \beta 2 \times 2$ subsystem of $\mathbf{W}_{\alpha, \beta, \gamma}$ in (8)-(10). Therefore, after application of (11) to the $\alpha \beta 2 \times 2$ subsystems, the plant model (8)-(10) can be written as

$$
v_{\alpha+j \beta}=\frac{R L_{L} s+R R_{L}}{L_{L} s+R+R_{L}} i_{\alpha+j \beta}+\frac{R}{L_{L} s+R+R_{L}} v g_{\alpha+j \beta} \text {. }
$$

It is important to note that since the load $R$ is balanced, the plant model given in (12) also holds for both the symmetric components of the currents and voltages. Hence, the negativesequence of (12) can be written as

$$
\begin{aligned}
v_{\alpha+j \beta}^{-} & =\frac{R L_{L} s+R R_{L}}{L_{L} s+R+R_{L}} i_{\alpha+j \beta}^{-}+\frac{R}{L_{L} s+R+R_{L}} v g_{\alpha+j \beta}^{-} \\
& =G^{-}(s) i_{\alpha+j \beta}^{-}+W^{-}(s) v g_{\alpha+j \beta}^{-}
\end{aligned}
$$

that provides a compact representation of the open-loop plant model, which can be represented in terms of block diagrams as in Fig. 2. The plant model (13) is a linear model with complex input and output variables. The plant input is the negativesequence current $i_{\alpha+j \beta}^{-}$, the plant output is the negativesequence voltage $v_{\alpha+j \beta}^{-}$, and the unbalance grid negativesequence voltage $v g_{\alpha+j \beta}^{-}$is viewed as a perturbation.

\section{B. Problem Formulation}

Given the plant model (13), the problem to be solved is to find the appropriate negative-sequence current $i_{\alpha+j \beta}^{-}$that eliminates the negative-sequence voltage, that is, such that $v_{\alpha+j \beta}^{-}=0$. It is important to note that $v_{\alpha+j \beta}^{-} \in \mathbb{C}$, which means that it has a modulus $|\cdot|$ and a phase $\theta(\cdot)$. Hence, to achieve $v_{\alpha+j \beta}^{-}=0$ means to have $\left|v_{\alpha+j \beta}^{-}\right|=0$ while $\theta\left(v_{\alpha+j \beta}^{-}\right)$ in this particular case is not defined.

\section{Problem Feasibility}

By taking (13), making $v_{\alpha+j \beta}^{-}=0$, and isolating $i_{\alpha+j \beta}^{-}$, the following expression is obtained

$$
i_{\alpha+j \beta}^{-}=\frac{1}{L_{L} s+R_{L}} v g_{\alpha+j \beta}^{-}
$$

which is a differential equation whose solution indicates that it does exist a current that eliminates the negative-sequence

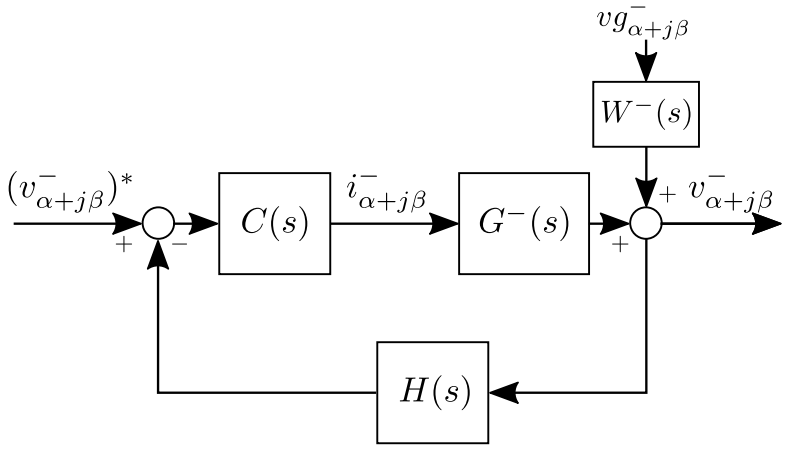

Fig. 3. Closed-loop system.

voltage. Therefore, the problem can be solved, but it would require a measure of the grid impedance $\left(R_{L}\right.$ and $\left.L_{L}\right)$, and a measure of the unbalanced voltage $v g_{\alpha+j \beta}^{-}$. However, none of these measures is available. Instead, the converter output voltages $v_{1,2,3}$ will be measured, then transformed into the $\alpha \beta$ stationary frame components, and then further transformed into the symmetric components via a SOGI. And only the complexificated negative-sequence component $v_{\alpha+j \beta}^{-}$will be used for the control purposes.

Schematically, the closed-loop configuration is given in Fig. 3, where the goal is to design the control $C(s)$ where the reference input is the negative-sequence voltage that is zero, $\left(v_{\alpha+j \beta}^{-}\right)^{*}=0$, and the sensor transfer function $H(s)$ corresponds to the SOGI.

\section{CONTROL PROPOSAL}

This section presents the new dissonant-resonant (DR) controller and establishes a comprehensive relation between the DR controller and a "untuned" standard resonant (R) controller in the $\alpha \beta$ frame. In addition, the stability analysis of the closed-loop system is provided, together with the controller design guidelines.

\section{A. Dissonant-Resonant (DR) Controller}

In order to solve the problem formulated in sub-section II-B, the following dissonant-resonant (DR) controller is proposed

$$
i_{\alpha+j \beta}^{-}=k e^{-j \omega_{0} t} \int e^{j \omega_{d} t}\left(\left|\left(v_{\alpha+j \beta}^{-}\right)^{*}\right|-\left|v_{\alpha+j \beta}^{-}\right|\right) \mathrm{d} t
$$

where $\omega_{0}$ is the grid frequency given by the SOGI-FLL (frequency locked loop) [37], and the integral gain $k \in \mathbb{C}$ and the dissonant frequency $\omega_{d}$ are the control parameters.

\section{B. From a $R$ Controller to a DR Controller}

A standard $\mathrm{R}$ controller in the stationary reference frame for the negative-sequence is given by [32]

$$
\left(\begin{array}{c}
i_{\alpha}^{-}(s) \\
i_{\beta}^{-}(s)
\end{array}\right)=\left(\begin{array}{cc}
\frac{K s}{s^{2}+\omega_{0}^{2}} & \frac{K \omega_{0}}{s^{2}+\omega_{0}^{2}} \\
-\frac{K \omega_{0}}{s^{2}+\omega_{0}^{2}} & \frac{K s}{s^{2}+\omega_{0}^{2}}
\end{array}\right)\left(\begin{array}{l}
\varepsilon_{\alpha}^{-}(s) \\
\varepsilon_{\beta}^{-}(s)
\end{array}\right)
$$

where $K \in \mathbb{R}$ is the integral gain, and $\varepsilon_{\alpha}^{-}(s)$ and $\varepsilon_{\beta}^{-}(s)$ are the voltage errors given by

$$
\varepsilon_{\alpha}^{-}(s)=\left(v_{\alpha}^{-}(s)\right)^{*}-v_{\alpha}^{-}(s), \varepsilon_{\beta}^{-}(s)=\left(v_{\beta}^{-}(s)\right)^{*}-v_{\beta}^{-}(s) .
$$


By noting that the complexification property (11) can be applied to (16), the $\mathrm{R}$ controller can also be written as

$$
i_{\alpha+j \beta}^{-}=\left(\frac{K s}{s^{2}+\omega_{0}^{2}}-j \frac{K \omega_{0}}{s^{2}+\omega_{0}^{2}}\right) \varepsilon_{\alpha+j \beta}^{-}
$$

which can be further rearranged as follows

$$
i_{\alpha+j \beta}^{-}=\frac{K s-j K \omega_{0}}{s^{2}+\omega_{0}^{2}} \varepsilon_{\alpha+j \beta}^{-}=\frac{K}{s+j \omega_{0}} \varepsilon_{\alpha+j \beta}^{-} .
$$

Note that the transfer function in (19) is a synchronous integrator in negative-sequence [42] in the $\alpha \beta$ frame. By applying the Laplace transform and related properties to (19), the following differential equation is obtained

$$
\frac{\mathrm{d} i_{\alpha+j \beta}^{-}}{\mathrm{d} t}+j \omega_{0} i_{\alpha+j \beta}^{-}=K \varepsilon_{\alpha+j \beta}^{-} .
$$

By assuming zero initial conditions, the solution of (20) is

$$
i_{\alpha+j \beta}^{-}=K e^{-j \omega_{0} t} \int e^{j \omega_{0} t} \varepsilon_{\alpha+j \beta}^{-} \mathrm{d} t
$$

which is a complexificated $\mathrm{R}$ controller in the $\alpha \beta$ frame. In order to avoid a "pure" integrator, controller (21) is modified adding a dissonant frequency $\omega_{d}$ to the system frequency $\omega_{0}$ of the exponential inside of the integral (future work will study the effect of this modification in the frequency of the exponential outside of the integral), which leads to

$$
i_{\alpha+j \beta}^{-}=K e^{-j \omega_{0} t} \int e^{j\left(\omega_{0}+\omega_{d}\right) t} \varepsilon_{\alpha+j \beta}^{-} \mathrm{d} t .
$$

The modification included in (22) can be explained as follows. Looking at (21), the negative-sequence voltage error $\varepsilon_{\alpha+j \beta}^{-}$ rotates at frequency $-\omega_{0}$ (for being the negative component). Hence, by multiplying it inside the integral by $e^{j \omega_{0} t}$ has the effect of cancelling the rotation. Then integration takes places, and the multiplication by the outside term $e^{-j \omega_{0} t}$ makes the obtained negative-sequence current to rotate again at frequency $-\omega_{0}$. The inclusion of the dissonant frequency $\omega_{d}$ in (22) does not permit a perfect cancellation of the frequency rotation of the negative-sequence voltage error $\varepsilon_{\alpha+j \beta}^{-}$, thus leading to a dissonant integrator.

By using the polar notation of the $\alpha \beta$ negative-sequence errors given in (17), the complexificated voltage error negativesequence $\varepsilon_{\alpha+j \beta}^{-}$can be written as

$$
\begin{aligned}
\varepsilon_{\alpha+j \beta}^{-} & =\left(v_{\alpha+j \beta}^{-}\right)^{*}-v_{\alpha+j \beta}^{-} \\
& =\left|\left(v_{\alpha+j \beta}^{-}\right)^{*}\right| e^{-j\left(\omega_{0} t-\varphi\right)}-\left|v_{\alpha+j \beta}^{-}\right| e^{-j\left(\omega_{0} t-\varphi^{\prime}\right)}
\end{aligned}
$$

where $\varphi$ and $\varphi^{\prime}$ are initial phases. Then, substituting (23) into (22), simplifying $\omega_{0}$ wherever possible, and removing the common factor $e^{j \varphi^{\prime}}$, the following expression is obtained

$$
\begin{gathered}
i_{\alpha+j \beta}^{-}=k e^{-j \omega_{0} t} \int e^{j \omega_{d} t}\left(\left|\left(v_{\alpha+j \beta}^{-}\right)^{*}\right| e^{j\left(\varphi-\varphi^{\prime}\right)}-\left|v_{\alpha+j \beta}^{-}\right|\right) \mathrm{d} t \\
\text { with } k=e^{j \varphi^{\prime}} K .
\end{gathered}
$$

Note that the term $\left|\left(v_{\alpha+j \beta}^{-}\right)^{*}\right| e^{j\left(\varphi-\varphi^{\prime}\right)}$ in (24) can be considered as a new negative-sequence voltage reference. Hence, making an abuse of notation, it could be re-defined as

$$
\left|\left(v_{\alpha+j \beta}^{-}\right)^{*}\right| \triangleq\left|\left(v_{\alpha+j \beta}^{-}\right)^{*}\right| e^{j\left(\varphi-\varphi^{\prime}\right)} .
$$

Using (26) and (25) in (24), the DR controller (15) is obtained.

\section{DR Controller Properties}

From the definition of the DR controller (15) and its relation to a standard $\mathrm{R}$ controller given in the previous subsection, the following properties can be highlighted. First, the gain (25) depends on the initial condition because of its dependency on the initial phase $\varphi^{\prime}$ in $e^{j \varphi^{\prime}}$. In fact, this term has a modulus equal to 1 , that is, it does not change the value of $K$, but points towards an undetermined direction, which creates uncertainty that may impact the closed-loop dynamic behavior. To overcome the problem that may arise for achieving repetitive experiments, the controller is activated when $\varphi^{\prime}=0$.

Second, when the dissonant frequency is $\omega_{d}=0$, the DR controller (15) operates like a standard R controller, as it can be observed in (22). Therefore it can be considered a generalization of the $\mathrm{R}$ controller which is an integral controller of the negative-sequence voltage error in modulus, rotated at frequency $-\omega_{0}$.

Third, looking at the control parameters of the DR controller, the integral gain $k$ can be used to boost performance and it is related to the final error. And the dissonant frequency $\omega_{d}$ affects the rotation frequency, thus providing a smooth transition from a proportional to an integral controller in terms of logical operation.

\section{Stability Analysis}

The plant transfer functions $G^{-}(s)$ and $W^{-}(s)$ in Fig. 3 are given in (13), the controller $C(s)$ is the DR controller (15), and the sensor $H(s)$ is the SOGI whose model characterized by a damping factor $\xi$ in complexificated form is [43]

$$
H(s)=\frac{\xi \omega_{0} s-j \xi \omega_{0}^{2}}{s^{2}+\xi \omega_{0} s+\omega_{0}^{2}} .
$$

Therefore, the stability analysis of the closed loop model illustrated in Fig. 3 can be performed using the closed-loop transfer function given by

$$
G_{C L}(s)=G(s) C(s)[1+H(s) G(s) C(s)]^{-1}
$$

where the minus subscript of $G^{-}(s)$ has been removed, the input and output are $\left(v_{\alpha+j \beta}^{-}\right)^{*}$ and $v_{\alpha+j \beta}^{-}$, respectively, and the controller transfer function $C(s)$ is computed next.

\section{A. Controller Transfer Function}

The transfer function is obtained as follows. First, by using again the polar notation, the modulus of the negative-sequence voltage $v_{\alpha+j \beta}^{-}$can be written as

$$
\left|v_{\alpha+j \beta}^{-}\right|=e^{j\left(\omega_{0} t+\varphi\right)} v_{\alpha+j \beta}^{-}
$$

By using (29), the DR controller (15) can be expressed as

$$
i_{\alpha+j \beta}^{-}=k e^{-j \omega_{0} t} \int e^{j \omega_{d} t}\left[\left|\left(v_{\alpha+j \beta}^{-}\right)^{*}\right|-e^{j\left(\omega_{0} t+\varphi\right)} v_{\alpha+j \beta}^{-}\right] d t
$$

By removing the common factor $e^{j \varphi}$ in (30) and performing some calculations, the DR controller is written as

$$
i_{\alpha+j \beta}^{-}=k e^{j \varphi} e^{-j \omega_{0} t} \int e^{j \omega_{d} t} e^{j \omega_{0} t}\left[\bar{v}^{*}-v_{\alpha+j \beta}^{-}\right] d t
$$


where

$$
\bar{v}^{*}=e^{-j \omega_{0} t-j \varphi}\left|\left(v_{\alpha+j \beta}^{-}\right)^{*}\right|
$$

becomes the new reference input but it does not affect the stability analysis. Note also that similar than the gain given in (25), the gain $k$ in (31) is multiplied by $e^{j \varphi}$. Hence, for each given $k$ value, the initial direction $\varphi$ will determine performance and the shape of the stability region.

In order to obtain the Laplace transform of (31), the derivative of (31) is performed to obtain

$$
\begin{aligned}
\frac{\mathrm{d} i_{\alpha+j \beta}^{-}}{\mathrm{d} t}= & -j \omega_{0} \underbrace{k e^{j \varphi} e^{-j \omega_{0} t} \int e^{j \omega_{d} t} e^{j \omega_{0} t}\left[\bar{v}^{*}-v_{\alpha+j \beta}^{-}\right] d t}_{i_{\alpha+j \beta}^{-}} \\
& +k e^{j \varphi} e^{j \omega_{d} t}\left[\bar{v}^{*}-v_{\alpha+j \beta}^{-}\right] \\
& =-j \omega_{0} i_{\alpha+j \beta}^{-}+k e^{j \varphi} e^{j \omega_{d} t}\left[\bar{v}^{*}-v_{\alpha+j \beta}^{-}\right]
\end{aligned}
$$

which can then be easily transformed into

$$
s I_{\alpha+j \beta}^{-}(s)=-j \omega_{0} I_{\alpha+j \beta}^{-}(s)+k e^{j \varphi} \mathcal{E}\left(s-j \omega_{d}\right)
$$

where the error $\mathcal{E}\left(s-j \omega_{d}\right)$ has been obtained using the frequency shifting property of the Laplace transform given by

$$
\mathcal{L}\left\{e^{a t} x(t)\right\}=X(s-a) .
$$

The controller transfer function can not be still obtained from (34) because the input $\mathcal{E}(\cdot)$ and the output $I_{\alpha+j \beta}^{-}(\cdot)$ have different arguments, $s-j \omega_{d}$ and $s$, respectively. This problem is solved applying the shift operator [44] given by

$$
x(t+a)=e^{a \frac{d}{d t}} x(t)
$$

Therefore, the application of (36) to the controller equation (34) leads to

$$
s I_{\alpha+j \beta}^{-}(s)=-j \omega_{0} I_{\alpha+j \beta}^{-}(s)+k e^{j \varphi} e^{-j \omega_{d} \frac{d}{d s}} \mathcal{E}(s)
$$

which can be further written as

$$
\begin{aligned}
C(s)=\frac{I_{\alpha+j \beta}^{-}(s)}{\mathcal{E}(s)} & =\left(s+j \omega_{0}\right)^{-1} k e^{j \varphi} e^{-j \omega_{d} \frac{d}{d s}} \\
& =\bar{C}(s) e^{-j \omega_{d} \frac{d}{d s}}
\end{aligned}
$$

\section{B. Stability Condition and Controller Design Guidelines}

At this point the closed loop transfer function in (28) can be constructed because transfer functions of the plant (13), SOGI (27) and controller (38) are available, while reminding that the new reference input is $\bar{v}^{*}(s)$ defined in the time domain in (32) and the output is $V_{\alpha+j \beta}^{-}(s)$.

By applying the push through rule to (28) it is obtained

$$
G_{C L}(s)=[1+G(s) C(s) H(s)]^{-1} G(s) C(s)
$$

which is nonlinear due to the non-linear expression of the controller $C(s)$ (38) caused by the presence of the $\frac{d}{d s}$ operator. By applying the small gain theorem [45], the closed loop system (39) will be stable if

$$
\left\|G(s) \bar{C}(s) H\left(s-j \omega_{d}\right) e^{-j \omega_{d} \frac{\mathrm{d}}{\mathrm{d} s}}\right\|_{\infty}<1
$$

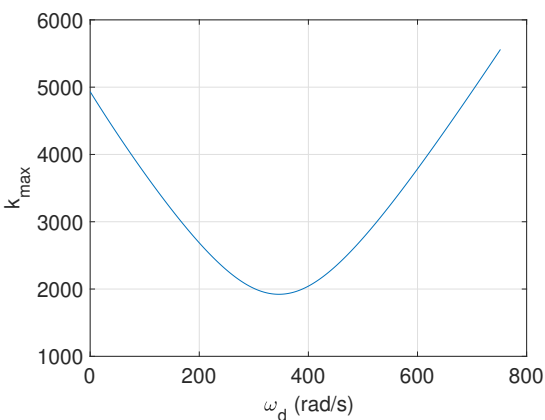

Fig. 4. Values of $k_{\max }$ as a function of $\omega_{d}$.

holds, where $\|\cdot\|_{\infty}$ denotes the infinite norm and the controller $C(s)$ has been replaced by he expression given in (38). By using the sub-multiplicative property of the norm, condition (40) can be written as

$$
\begin{aligned}
& \left\|G(s) \bar{C}(s) H\left(s-j \omega_{d}\right) e^{-j \omega_{d} \frac{\mathrm{d}}{\mathrm{d} s}}\right\|_{\infty} \\
& \leq\left\|G(s) \bar{C}(s) H\left(s-j \omega_{d}\right)\right\|_{\infty}\left\|e^{-j \omega_{d} \frac{\mathrm{d}}{\mathrm{d} s}}\right\|_{\infty}<1
\end{aligned}
$$

By noting that the norm of the shift operator is 1 , the stability condition (41) simplifies to

$$
\left\|G(s) \bar{C}(s) H\left(s-j \omega_{d}\right)\right\|_{\infty}<1
$$

By replacing in the stability condition (42) the transfer functions of the plant (13), SOGI (27) and controller (38), a relation is stablished between the dissonant frequency and the controller gain in terms of stability. In particular, for a given dissonant frequency $\omega_{d}$ and by solving the inequality (42), an upper bound for the modulus of the controller gain $k$, namely $k_{\max }$, is obtained. For example, by taking one of the values for the dissonant frequency that is used in the experiments presented in next section, $\omega_{d}=174 \mathrm{rad} / \mathrm{s}$, the inequality (42) becomes the expression given in (43), whose solution for $k$ provides a value $k_{\max } \simeq 3000$. Fig. 4 shows the $k_{\max } / \omega_{d}$ dependency by varying the dissonant frequency from $\omega_{d}=0$ to $\omega_{d}=2 \omega_{0}$, being $\omega_{0}=2 \pi 60$. It is important to note that stability is determined by the modulus of $k$. However, the shape of the system response is determined by its angle, which is given by the relation of its real and imaginary part.

\section{EXPERIMENTAL RESULTS}

The proposed control strategy has been tested in the laboratory set-up given in Fig. 5 where six grid-feeding converters operate in a grid-connected AC microgrid. Two scenarios are considered. First, the basic scenario that mimics the scheme shown in Fig. 1 where a single grid-feeding converter, $G_{1}$ in Fig. 5, enabled with the DR controller is connected to an unbalanced grid while supplies the local load $L_{1}$. In this basic scenario, the rest of converters $\left(G_{2}\right.$ to $\left.G_{6}\right)$ of Fig. 5 are disabled. And second, the parallel scenario where the six grid-feeding converters connected to an unbalanced grid are also enabled with DR controllers. Each grid-feeding converter is implemented using a Guasch three-phase inverter with a damped LC-filter and a DY transformer. The input of the 


$$
\left\|G(s) \bar{C}(s) H\left(s-j \omega_{d}\right)\right\|_{\infty}=\left\|-\frac{k\left(L_{L} R s+R R_{L}\right)\left(\xi \omega_{0}^{2} j-\xi \omega_{0}\left(s-\omega_{d} j\right)\right)}{\left(L_{L} s+\left(R+R_{L}\right)\right)\left(s+\omega_{d} j\right)\left(\left(s-\omega_{d} j\right)^{2}+\omega_{0}^{2}+\xi \omega_{0}\left(s-\omega_{d} j\right)\right)}\right\|_{\infty}<1
$$

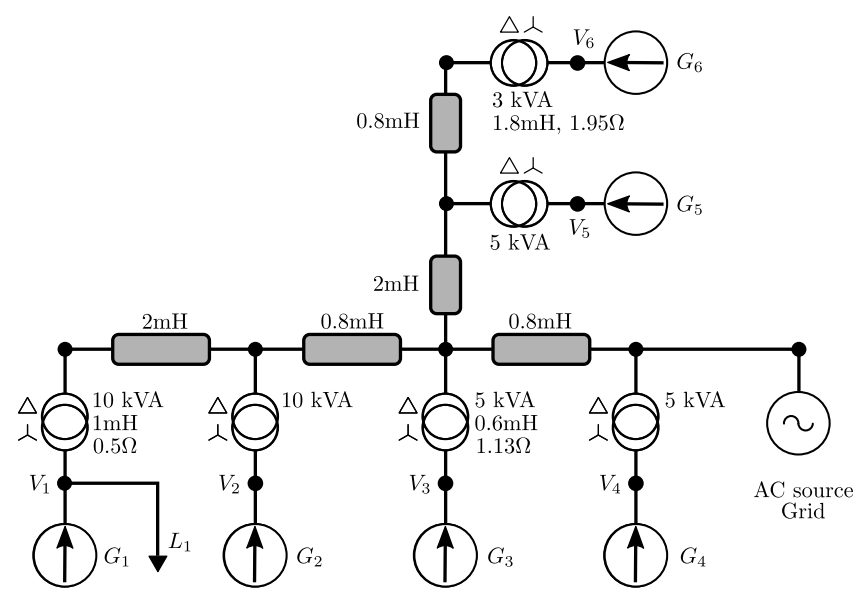

Fig. 5. Plant scheme for parallel operation.

TABLE I

NOMINAL VALUES OF THE SYSTEM SET-UP.

\begin{tabular}{lcc}
\hline \hline Description & symbol & nominal value \\
\hline nominal power & $S_{n}$ & $3.5 \mathrm{kVA}$ \\
DC-link voltage & $v g$ & $400 \mathrm{~V}$ \\
grid voltage & $\omega_{0}$ & $2 \pi 60 \mathrm{~V}(1-\mathrm{n}, \mathrm{peak})$ \\
grid frequency & $L_{L}$ & $4.6 \mathrm{mH}$ \\
grid inductance & $R_{L}$ & $0.5 \Omega$ \\
grid resistance & & $5 \mathrm{mH}$ \\
LC filter inductances & & $1.5 \mu \mathrm{F}$ \\
LC filter capacitances & & $68 \Omega$ \\
LC filter damping resistors & & $10 \mathrm{kVA}$ \\
$T_{1}$ and $T_{2}$ power rating & & $5 \mathrm{kVA}$ \\
$T_{3}, T_{4}$ and $T_{5}$ power rating & & $3 \mathrm{kVA}$ \\
$T_{6}$ power rating & & $0.5+3.7 \mathrm{j} \Omega$ \\
$T_{1}$ and $T_{2}$ equivalent impedance & $1.13+2.2 \mathrm{j} \Omega$ \\
$T_{3}, T_{4}$ and $T_{5}$ equivalent impedance & & $1.95+6.77 \mathrm{j} \Omega$ \\
$T_{6}$ equivalent impedance & $R$ & $24 \Omega$ \\
nominal local load & & $10 \mathrm{kHz}$ \\
switching frequency & $\xi$ & 0.707 \\
SOGI damping factor & &
\end{tabular}

converter is supplied by an Amrel DC power source. The grid is emulated by a Pacific Power AC power source with a grid impedance emulated using discrete RL impedances. For the basic scenario, the setup is configured to have the single converter $G_{1}$ injecting $600 \mathrm{~W}$ of active power. The main setup parameters are listed in Table I such as the components of the six LC filters, which are all equal, and the characteristics of the six DY transformers that interface each converter in Fig. 5. In Table I transformers are named as $T_{i}, i=1, \ldots, 6$, and they are not all equal, which permits configuring different types of connections.

It is important to note that for both basic and parallel scenarios being analyzed, the impedance value is abnormally high. This unrealistic weak characterization has been chosen on purpose to maximize the problem to be solved, which also permits observing the performance of the DR controller in a more accurate way. The operation of the proposal has been also successfully verified in more conventional grid conditions.
Note also that although the grid impedance has a given value, the DR controller does not need to know it for successfully achieving the control goal.

The DR controller is implemented on a Texas Instruments F28M36 digital signal processor. The sequence extractor and the internal controllers for the current loop are based on SOGI-FLLs. The current loop also includes a space vector modulator to compute the switching times of each converter branch. Phase voltages and currents are measured and exported to Matlab. In the experiments, at time $t=0 \mathrm{~s}$ the grid is unbalanced, and the amplitude of the $G_{1}$ negative-sequence voltage is $5 \mathrm{~V}$, which gives an unbalance factor of $3.2 \%$, thus being above of the recommended limit of $2 \%$ given by the EN 50160 standard. Then, for the basic scenario, the DR controller is activated at time $t=0.2 \mathrm{~s}$.

\section{A. Main Result}

Fig. 6 shows the performance and main actors of the proposed controller for negative-sequence voltage elimination for the basic scenario. Sub-fig. 6a shows the modulus of negative-sequence voltage $\left|v_{\alpha+j \beta}^{-}\right|$that starts with an initial value near $5 \mathrm{~V}$, and after applying the DR controller at time $t=0.2 \mathrm{~s}$, it starts to decrease towards zero, meeting the control goal that motivated its development. In this experiment, the control parameters are specified to be the gain $k$ with $\operatorname{Im}\{k\}=0$ and $\operatorname{Re}\{k\}=1400$ (and therefore initial phase $\varphi^{\prime}=0$ ) with a dissonant frequency $\omega_{d}=174 \mathrm{rad} / \mathrm{s}$, which are appropriate settings according to the design guidelines given in the previous section because the stability limit for this frequency was with $k_{\max } \simeq 3000$. In addition, the real and imaginary part of the controller gain $k$ are illustrated using an arrow representing a vector in a real-imaginary circle also plotted in the Sub-fig.

Fig. 6 shows also other signals of interest. Voltages $v_{a, b, c}$ are not shown because the unbalance is difficult to be observed. Instead, $\alpha \beta$ negative-sequence voltage $v_{\alpha}^{-}$and $v_{\beta}^{-}$(Subfig. 6b), and currents $i_{a, b, c}$ (Sub-fig. 6c) are displayed. To better illustrate the results, two zoom-in views of the currents $i_{a, b, c}$ are also presented in Sub-fig. 6d and 6e that correspond to the initial and final part of the experiment, respectively plotted with different $\mathrm{x}$-axis. Sub-fig. 6d shows the currents $i_{a, b, c}$ when the voltage unbalance is present and not action is taken to remove it (from time $t=0.1 \mathrm{~s}$ to $t=0.16 \mathrm{~s}$ ), which implies currents perfectly balanced. Alternatively, Sub-fig. 6e shows the currents $i_{a, b, c}$ after $1 \mathrm{~s}$ when voltages have already been balanced by the unbalance of the currents achieved by the action of the controller (from time $t=1.1 \mathrm{~s}$ to $t=1.16$ s). The unbalanced currents achieve balance in voltages by eliminating the negative-sequence voltage.

Fig. 7 complements Fig. 6 by illustrating the existing decoupling in steady-state dynamics for both positive and negative-sequence controllers while showing their coupling in the transient. In particular, Fig. 7 shows the performance 


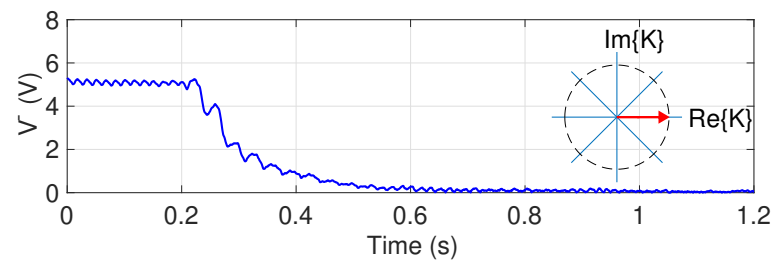

(a)

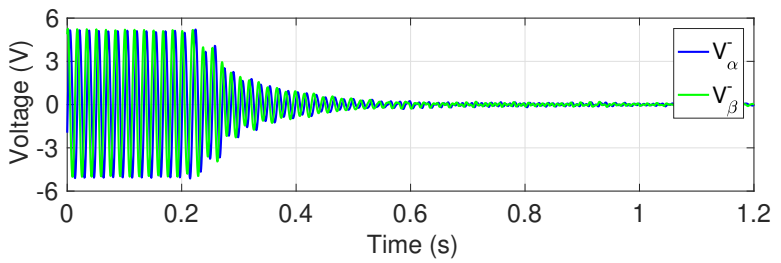

(b)

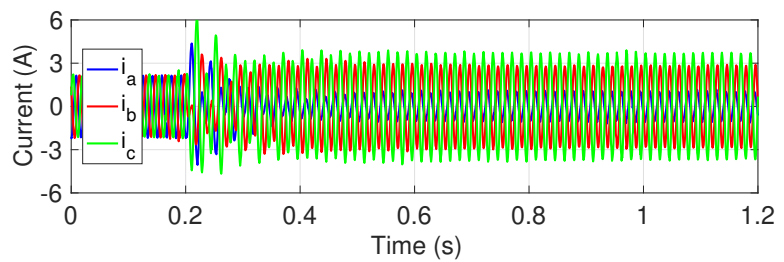

(c)

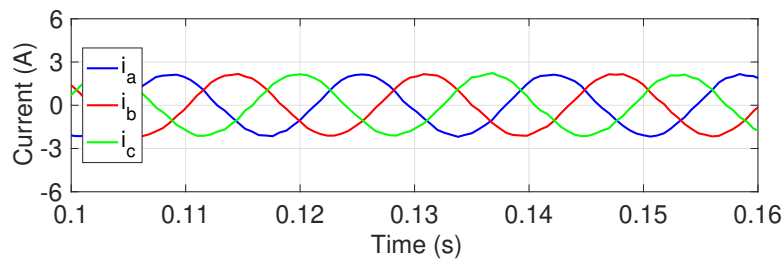

(d)

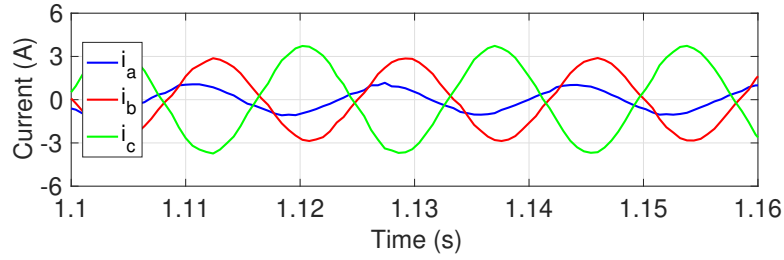

(e)

Fig. 6. Performance of the DR controller using gain $k$ with $\operatorname{Im}\{k\}=0$ and $\operatorname{Re}\{K\}=1400$, with $\omega_{d}=174 \mathrm{rad} / \mathrm{s}$ : (a) modulus of negative-sequence voltage, (b) $\alpha \beta$ negative-sequence voltages, (c) currents $i_{a, b, c}$, (d) currents $i_{a, b, c}$ zoom-in before applying the controller and (e) currents $i_{a, b, c}$ zoom-in after applying the controller.

of the same DR controller when the converter is subject to a change in active power injection. A load change at time $t=0.8 \mathrm{~s}$ occurs and requires doubling the active power injection, increasing from $600 \mathrm{~W}$ to $1200 \mathrm{~W}$. As it can be observed, the increase in the power injection leads to an increase in the injected currents (Sub-fig. 7b) while the negativesequence voltage (Sub-fig. 7a) reaches the expected steadystate equilibrium although a small overshoot can be observed when the load change occurs due to the coupling introduced by the SOGI. This experiment permits corroborating that the DR controller operates as desired without altering or being altered by the positive-sequence controller whose main task is to inject the active power generated by the source.

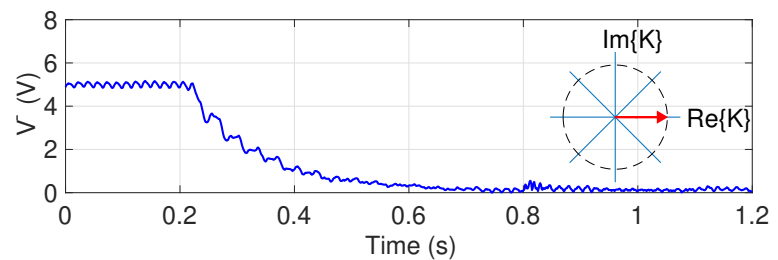

(a)

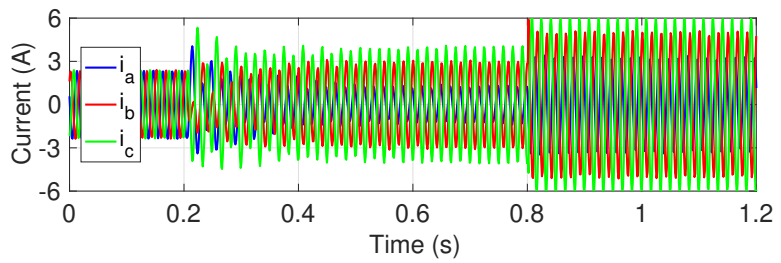

(b)

Fig. 7. Performance of the DR controller subject to a change in active power injection from $600 \mathrm{~W}$ to $1200 \mathrm{~W}$ at time $t=0.8 \mathrm{~s}$, using gain $k$ with $\operatorname{Im}\{k\}=0$ and $\operatorname{Re}\{K\}=1400$, with $\omega_{d}=174 \mathrm{rad} / \mathrm{s}$ : (a) modulus of negative-sequence voltage and (b) currents $i_{a, b, c}$.

\section{B. Real and Complex Part of the DR Controller Gain}

Similar to Sub-fig. 6a, Fig. 8 shows the performance of the DR controller for different initial phases of the controller gain. As before, the different settings of the real and imaginary part of the controller parameters are illustrated by the vector arrow plotted in each Sub-fig. As it can be observed, the phase of the gain $k$ has an effect on the transient dynamics. Nevertheless, for any phase, the DR controller is able to eliminate the negative-sequence voltage.

Fig. 9 shows the performance of the DR controller for different settings of the modulus of the controller gain $k$. The real and imaginary part of the controller gain keep the same angle but its modulus increase in each Sub-fig., from left to right. As it can be seen, the greater the gain, the faster the response. However, from $|k|=2800$ the system is no longer stable, as it can be seen for $|k|=3000$ in Sub-fig. 9d, thus corroborating the numerical study given in sub-section IV-B.

\section{Enriching the Closed-Loop Dynamics}

The dissonant frequency $\omega_{d}$ is the parameter of the DR controller (15) that permits generalizing the operation of a standard R controller in such a way that a richer set of closed-loop dynamics can be obtained. Fig. 10 shows the performance of the DR controller for different settings of the dissonant frequency in such a way that different pairs of $\left(\omega_{d},|k|\right)$ apply. In the experiments, the variation of $\omega_{d}$ goes together with a variation of the modulus of the controller gain in order to achieve in all the experiments the same settling time with different dynamics. In particular, from left to right, Sub-figures 10a, 10b and 10c are characterized by $\left(\omega_{d},|k|\right)=$ $\{(17.4,140),(174,1400),(1740,14000)\}$, respectively, where $\omega_{d}$ is in $\mathrm{rad} / \mathrm{s}$. This rich set of dynamics could not be achieved by a standard $\mathrm{R}$ controller.

In addition, Fig. 11 provides a comparison of the DR controller with a given particular setting, $|k|=1400$ and $\omega_{d}=174 \mathrm{rad} / \mathrm{s}$, with respect to a $\mathrm{R}$ controller with the same gain. As it can be observed, the $\mathrm{R}$ controller also 


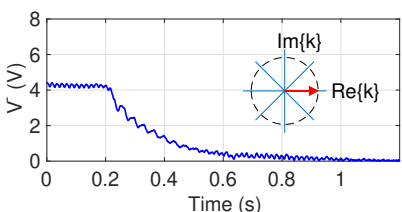

(a)

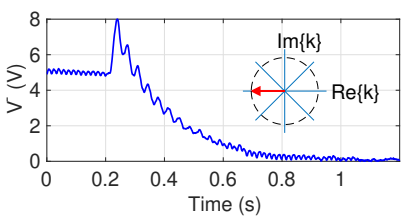

(e)

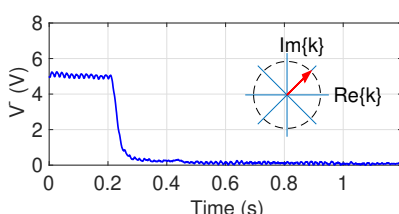

(b)

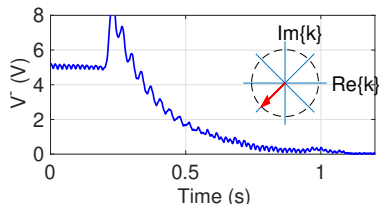

(f)

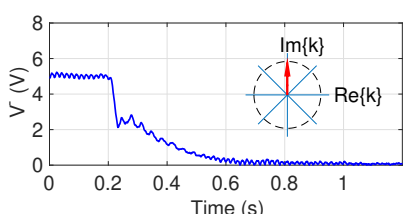

(c)

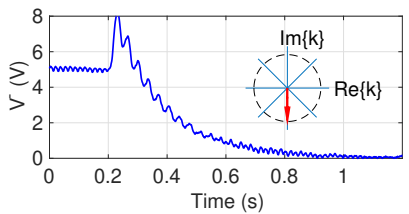

(g)

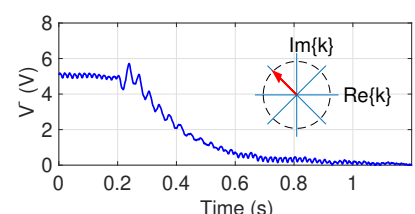

(d)

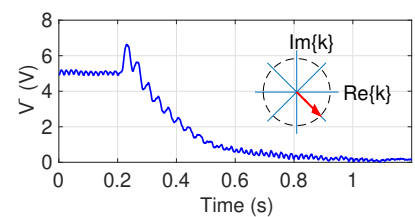

(h)

Fig. 8. Modulus of the negative-sequence voltage for different settings of the controller gain $k$ subject to $|k|=1400$, with $\omega_{d}=174$ rad/s: (a) $\varphi^{\prime}=0^{\circ}$, (b) $\varphi^{\prime}=45^{\circ}$, (c) $\varphi^{\prime}=90^{\circ}$, (d) $\varphi^{\prime}=135^{\circ}$, (e) $\varphi^{\prime}=180^{\circ}$, (f) $\varphi^{\prime}=225^{\circ}$, (g) $\varphi^{\prime}=270^{\circ}$, and (h) $\varphi^{\prime}=315^{\circ}$.

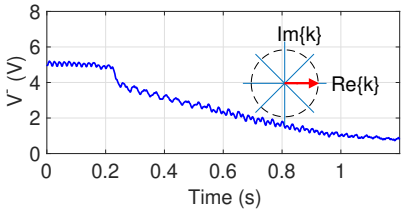

(a)

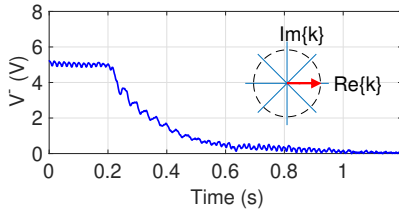

(b)

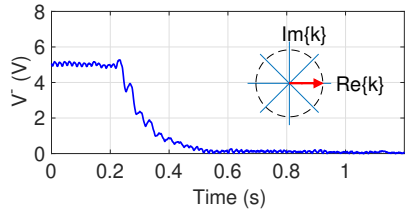

(c)

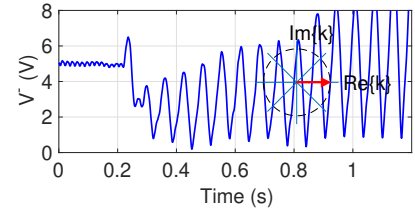

(d)

Fig. 9. Modulus of the negative-sequence voltage for different settings of the controller gain $k$, with $\omega_{d}=174 \mathrm{rad} / \mathrm{s}, \operatorname{Im}\{k\}=0$ and (a) $\operatorname{Re}\{k\}=700$, (b) $\operatorname{Re}\{k\}=1400$, (a) $\operatorname{Re}\{K\}=2000$, (a) $\operatorname{Re}\{K\}=3000$.

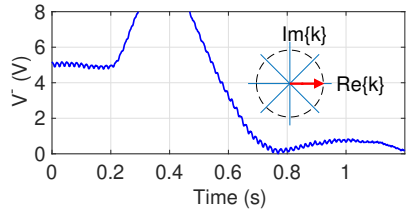

(a)

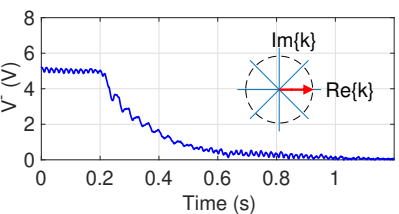

(b)

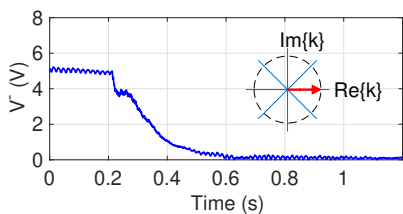

(c)

Fig. 10. Modulus of the negative-sequence voltage for different settings of the controller rotation speed $\omega_{d}$, that leads to different pairs of $\left(\omega_{d},|k|\right)$ : (a) $(17.4,140)$, (b) $(174,1400)$, and (c) $(1740,14000)$ (where $\omega_{d}$ is in $\left.\mathrm{rad} / \mathrm{s}\right)$.

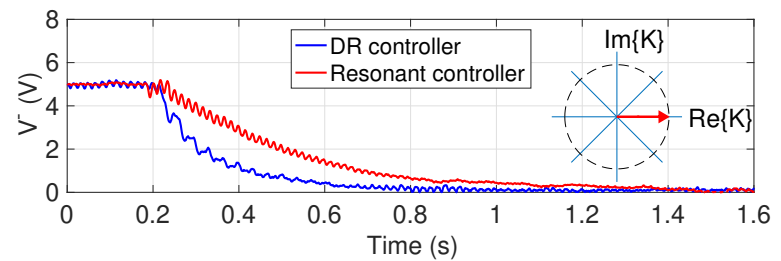

Fig. 11. Modulus of negative-sequence voltage of the DR controller using gain $k$ with $\operatorname{Im}\{k\}=0$ and $\operatorname{Re}\{k\}=1400$, with $\omega_{d}=174 \mathrm{rad} / \mathrm{s}$ compared to the standard resonant controller with $|k|=1400$.

eliminates the negative-sequence voltage. But the transient dynamics of the $\mathrm{R}$ controller are slower that the DR controller. Specifically, looking at the settling time where the negativesequence voltage remains within $5 \%$ of zero, the DR controller reaches this point at time $t=0.6 \mathrm{~s}$ while the $\mathrm{R}$ controller does it at time $t=1.1 \mathrm{~s}$, suggesting that the DR controller is almost two times faster than the $\mathrm{R}$ controller when both controllers are characterized by the same integral gain.

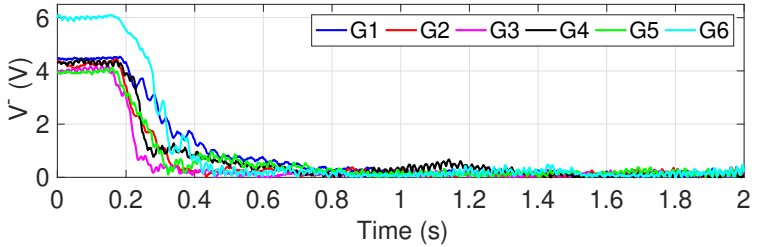

(a)

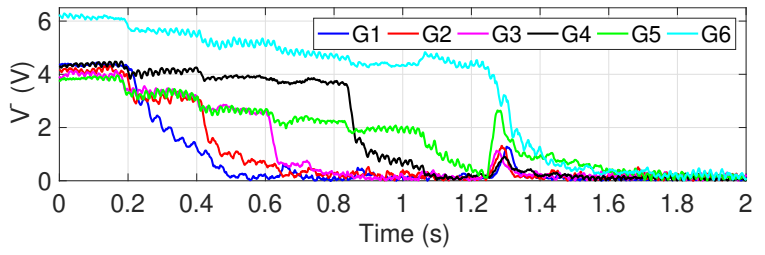

(b)

Fig. 12. Negative-sequence voltage elimination for parallel DR controllers: synchronized (a) and serial (b) activation.

\section{Parallel Operation}

Fig. 12 completes the experimental validation of the DR controller analyzing its performance in parallel operation when six grid-feeding converters operate in a grid-connected $\mathrm{AC}$ 
microgrid, as illustrated in Fig. 5. In this scenario, the voltage of the main grid is unbalanced and the converters are supplying the load $L_{1}$ with $100 \mathrm{~W}$ each. For each converter, the damped LC filter and the DY transformer specifications are given in Table I. The goal of each local DR controller is to eliminate the negative-sequence voltage seen in each converter output. Two experiments are performed. The first one, Sub-figure 12a, covers the synchronized activation of the six DR controllers of the six converters, meaning that all of them are activated at the same time, at $t=0.2 \mathrm{~s}$. The second one, Sub-figure $12 \mathrm{~b}$, covers the serial activation of the six DR controllers. In this case, starting at $t=0.2 \mathrm{~s}$, and every $0.2 \mathrm{~s}$ approximately, every DR controller is activated, starting from $G_{1}$ to $G_{6}$. Both subfigures in Fig. 12 shows that all DR controllers eliminate the negative-sequence voltage. It is worth noting that the serial activation covers the wort case scenario in terms of coupling effects among the controllers. In particular, it illustrates the coupling effect that each activation of each converter DR controller has in the negative-sequence voltage seen by the other converters. The performance of each controller after the activation of a new one highly depends on the initial phase that it has to deal with, which determines the closed-loop dynamic behavior delivered by each controller, as discussed in the description of the properties of the DR controller given in Sub-section III-C.

\section{CONCLUSION}

The elimination of voltage unbalance leads to higher power quality. Motivated by this fact, this paper has presented a novel controller strategy for a grid-feeding converter capable of suppressing the negative-sequence voltage at the converter output. The control strategy, based on the application of a resonant controller, defines a generalized structure, called dissonant-resonant controller, that is characterized by two control parameters whose adjustment permits the controller to act almost like a pure integral controller. As a consequence, it has the ability of completely remove the error, that is, to remove the negative-sequence voltage without incurring in the problems that integral controllers may have in parallel operation. In addition, the control goal is achieved regardless of the impedance value of the grid. The presented stability analysis permits a safe design while indicating design guidelines for the control parameters. Future work will focus on the extension of this control algorithm to grid-forming converters.

\section{REFERENCES}

[1] F Woll, "Effect of unbalanced voltage on the operation of polyphase induction motors," IEEE Trans. Ind. Applicat., vol 11, pp 3842, Jan. 1975.

[2] K. Lee, G. Venkataramanan and T. M. Jahns, "Modeling effects of voltage unbalances in industrial distribution systems with adjustablespeed drives," IEEE Trans Ind. Applicat., vol. 44, no. 5, pp. 1322-1332, Sept.-Oct. 2008.

[3] "EN 50160, Voltage characteristics of electricity supplied by public electricity networks", 1999

[4] J. Rocabert, A. Luna, F. Blaabjerg and P. Rodríguez, "Control of power converters in AC microgrids," IEEE Trans. Power Electron., vol. 27, no. 11, pp. 4734-4749, Nov. 2012.

[5] D. Graovac, V. A. Kati, and A. Rufer, "Power quality problems compenation with universal power quality conditioning system," IEEE Trans. Power Del., vol. 22, no. 2, pp. 968-976, Apr. 2007.
[6] J. Miret, A. Camacho, M. Castilla, L. G. Vicuna, and J. Matas, "Voltage support control strategies for static synchronous compensators under unbalanced voltage sags," IEEE Trans. Ind. Electron., vol. 61, no. 2, pp. 808-820, Apr. 2013.

[7] J. M. Guerrero, P. C. Loh, T. L. Lee, and M. Chandorkar, "Advanced control architectures for intelligent microgrids. Part II: Power quality, energy storage, and AC/DC microgrids," IEEE Trans. Ind. Electron., vol. 60, no. 4, pp. 1263-1270, Apr. 2013.

[8] A. Camacho, M. Castilla, J. Miret, J. C. Vasquez, and E. Alarcon-Gallo, "Flexible voltage support control for three-phase distributed generation inverters under grid fault," IEEE Trans. Ind. Electron., vol. 60, no. 4, pp. 1429-1441, April 2013.

[9] F. Gonzalez-Espin, I. Patrao, E. Figueres and G. Garcera, "An adaptive digital control technique for improved performance of grid connected inverters," IEEE Trans. Ind. Inf., vol. 9, no. 2, pp. 708-718, May 2013.

[10] M. Castilla, J. Miret, A. Camacho, J. Matas and L. García de Vicuña, "Voltage support control strategies for static synchronous compensators under unbalanced voltage sags," IEEE Trans. Ind. Electron. vol. 61, no. 2, pp. 808-820, Feb. 2014.

[11] X. Guo, X. Zhang, B. Wang, W. Wu, and J. M. Guerrero, "Asymmetrical grid fault ride-through strategy of three-phase grid-connected inverter considering network impedance impact in low-voltage grid," IEEE Trans. Power Electron., vol. 29, no. 3, pp. 1064-1068, Mar. 2014.

[12] A. Camacho, M. Castilla, J. Miret, R. Guzman, and A. Borrell, "Reactive power control for distributed generation power plants to comply with voltage limits during grid faults," IEEE Trans. Power Electron., vol. 29 , no. 11, pp. 6224-6234, Nov. 2014.

[13] X. Shi, Z. Wang, B. Liu, Y. Liu, L. M. Tolbert and F. Wang, "Characteristic investigation and control of a modular multilevel converter-based HVDC system under single-line-to-ground fault conditions," IEEE Trans. Power Electron., vol. 30, no. 1, pp. 408-421, Jan. 2015.

[14] S. Li, X. Wang, Z. Yao, T. Li and Z. Peng, "Circulating current suppressing strategy for MMC-HVDC based on nonideal proportional resonant controllers under unbalanced grid conditions," IEEE Trans. Power Electron., vol. 30, no. 1, pp. 387-397, Jan. 2015.

[15] M. Mirhosseini, J. Pou, and V. G. Agelidis, "Individual phase current control with the capability to avoid overvoltage in grid-connected photovoltaic power plants under unbalanced voltage sags," IEEE Trans. Power Electron., vol. 30, no. 10, pp. 5346-5351, Oct 2015.

[16] J. L. Sosa, M. Castilla, J. Miret, J. Matas, and Y. A. Al-Turki, "Control strategy to maximize the power capability of PV three-phase inverters during voltage sags," IEEE Trans. Power Electron., vol. 31, no. 4, pp. 3314-3323, April 2016.

[17] H. Nian, T. Wang, and Z. Q. Zhu, "Voltage imbalance compensation for doubly fed induction generator using direct resonant feedback regulator," IEEE Trans. Energy Convers., vol. 31, no. 2, pp. 614-626, Jun. 2016.

[18] F. Nejabatkhah, Y. W. Li and B. Wu, "Control strategies of three-phase distributed generation inverters for grid unbalanced voltage compensation," IEEE Trans. Power Electron., vol. 31, no. 7, pp. 5228-5241, July 2016.

[19] Z. Wang, B. Wu, D. Xu, M. Cheng, L. Xu, ”DC-link current ripple mitigation for current-source grid-connected converters under unbalanced grid conditions", IEEE Trans. Ind. Electron., vol. 63, no. 8, pp. $4967-$ 4977, Aug. 2016.

[20] V. Vekhande, K. V. K. and B. G. Fernandes, "Control of three-phase bidirectional current-source converter to inject Balanced three-phase currents under unbalanced grid voltage condition," IEEE Trans. Power Electron., vol. 31, no. 9, pp. 6719-6737, Sept. 2016.

[21] Y. Hu, Z. Q. Zhu and M. Odavic, 'Instantaneous power control for suppressing the second-harmonic DC-bus voltage under generic unbalanced operating conditions," IEEE Trans. Power Electron., vol. 32, no. 5, pp. 3998-4006, May 2017.

[22] X. Shi, Z. Wang, B. Liu, Y. Li, L. M. Tolbert and F. Wang, "Steadystate modeling of modular multilevel converter under unbalanced grid conditions," IEEE Trans. Power Electron., vol. 32, no. 9, pp. 7306-7324, Sept. 2017.

[23] H. Chen and X. Xing, "Circulating current analysis and suppression for module grid-connected inverters under unbalanced conditions," IEEE Access, vol. 6, pp. 69120-69129, Oct. 2018

[24] M. A. G. López, J. L. G. de Vicuña, J. Miret, M. Castilla, and R. Guzmán, "Control strategy for grid-connected three-phase inverters during voltage sags to meet grid codes and to maximize power delivery capability," IEEE Trans. Power Electron., vol. 33, no. 11, pp. 9360-9374, Nov. 2018.

[25] X. Guo, Y. Yang and X. Zhang, "Advanced control of grid-connected current source converter under unbalanced grid voltage conditions," IEEE Trans. Ind. Electron., vol. 65, no. 12, pp. 9225-9233, Dec. 2018. 
[26] M. M. Shabestary and Y. A. I. Mohamed, "Asymmetrical ride-through and grid support in converter-interfaced DG units under unbalanced conditions," IEEE Trans. Ind. Electron., vol. 66, no. 2, pp. 1130-1141, Feb. 2019.

[27] C. Guo, J. Yang and C. Zhao, "Investigation of small-signal dynamics of modular multilevel converter under unbalanced grid conditions," IEEE Trans. Ind. Electron., vol. 66, no. 3, pp. 2269-2279, March 2019.

[28] F. H. Md Rafi, M. J. Hossain, G. Town and J. Lu, "Smart voltage-source inverters with a novel approach to enhance neutral-current compensation," IEEE Trans. Ind. Electron., vol. 66, no. 5, pp. 3518-3529, May 2019.

[29] B. A. Francis and W. M. Wonham, "The internal model principle for linear multivariable regulators," J. Appl. Maths. Optim., vol. 2, no. 2, pp. 170-194, 1975.

[30] D. N. Zmood, D. G. Holmes and G. H. Bode, "Frequency-domain analysis of three-phase linear current regulators," IEEE Trans. Ind. Appl., vol. 37, no. 2, pp. 601-610, March-April 2001.

[31] S. Fukuda and R. Imamura, "Application of a sinusoidal internal model to current control of three-phase utility-interface converters," IEEE Trans. Ind. Electron., vol. 52, no. 2, pp. 420-426, Apr. 2005

[32] R. Teodorescu, F. Blaabjerg, M. Liserre and P. C. Loh, "Proportionalresonant controllers and filters for grid-connected voltage-source converters," in IEE Proceedings - Electric Power Applications, vol. 153, no. 5, pp. 750-762, September 2006.

[33] A. Timbus, M. Liserre, R. Teodorescu, P. Rodriguez, and F. Blaabjerg, "Evaluation of current controllers for distributed power generation systems," IEEE Trans.Power Electron., vol.24, no.3, pp. 654-664, Mar. 2009.

[34] M.E. Meral, D. Celík, "A comprehensive survey on control strategies of distributed generation power systems under normal and abnormal conditions, Annual Reviews in Control, in press, 2019.

[35] C. L. Fortescue, "Method of symmetrical co-ordinates applied to the solution of polyphase networks," Trans. Am. Inst. Elec. Eng., vol. XXXVII, no. 2, pp. 1027-1140, Jul. 1918.

[36] F. J. Rodríguez, E. Bueno, M. Aredes, L. G. B. Rolim, F. A. S. Neves, and M. C. Cavalcanti, "Discrete-time implementation of second order generalized integrators for grid converters," in 34th Annu. Conf. of IEEE Ind. Electron., Nov. 2008, pp. 176-181.

[37] S. Golestan, A. Vidal, A. G. Yepes, J. M. Guerrero, J. C. Vasquez and J. Doval-Gandoy, "A true open-loop synchronization technique," IEEE Trans. Ind. Informat., vol. 12, no. 3, pp. 1093-1103, June 2016.

[38] Z. Xin, R. Zhao, P. Mattavelli, P. C. Loh, and F. Blaabjerg, "Reinvestigation of generalized integrator based filters from a first-ordersystem perspective," IEEE Access, vol. 4, pp. 7131-7144, 2016.

[39] M. Andreasson, D. V. Dimarogonas, H. Sandberg and K.H. Johansson, "Distributed control of networked dynamical systems: static feedback, integral action and consensus", IEEE Trans. Automatic Control, vol. 59 no. 7 , pp.1750 -1764, 2014.

[40] F. Dörfler, J. W. Simpson-Porco and F. Bullo, "Breaking the hierarchy: distributed control and economic optimality in microgrids," IEEE Trans. Control Netw. Syst., vol. 3, no. 3, pp. 241-253, Sept. 2016.

[41] P. R. Halmos, Finite-Dimensional Vector Spaces, Springer-Verlag, New York, 1974.

[42] C. A. Busada, S. Gomez Jorge, A. E. Leon and J. A. Solsona, "Current controller based on reduced order generalized integrators for distributed generation systems," IEEE Trans. Ind. Electron., vol. 59, no. 7, pp. 28982909, July 2012

[43] P. Rodríguez, A. Luna, R. S. Muñoz-Aguilar, I. Etxeberria-Otadui, R. Teodorescu and F. Blaabjerg, "A stationary reference frame grid synchronization system for three-phase grid-connected power converters under adverse grid conditions," IEEE Trans. Power Electron., vol. 27, no. 1, pp. 99-112, Jan. 2012.

[44] J.R. Partington, Linear operators and linear systems: an analytical approach to control theory, London Mathematical Society Student Texts, Cambridge University Press, 2004

[45] H.K. Khalil, Nonlinear Systems. Third Edition, Prentice Hall, 2001.

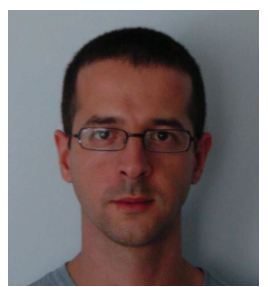

Manel Velasco graduated in maritime engineering in 1999 and received the $\mathrm{PhD}$ degree in automatic control in 2006, both from the Technical University of Catalonia, Barcelona, Spain. Since 2002, he has been an assistant professor in the Department of Automatic Control at the Technical University of Catalonia. His research interests include artificial intelligence, real-time control systems, and collaborative control systems, especially on redundant controllers and multiple controllers with self-interacting systems.

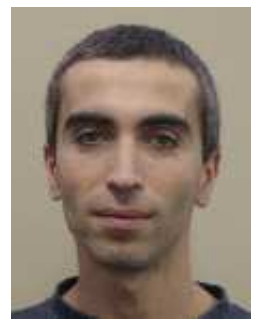

Pau Martí received the degree in computer science and the $\mathrm{PhD}$ degree in automatic control from the Technical University of Catalonia, Barcelona, Spain, in 1996 and 2002, respectively. Since 1996 he has held different teaching/research positions in the Department of Automatic Control at the Technical University of Catalonia, where he is currently an Associate Professor. His research interests include embedded and networked control systems, nonlinear control and microgrids.

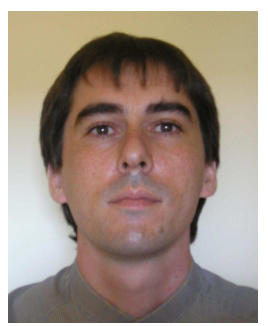

Antonio Camacho received the B.S. degree in chemical engineering, the M.S. degree in automation and industrial electronics, and the Ph.D. degree in electronic engineering, from the Technical University of Catalonia, Barcelona, Spain in 2000, 2009 and 2015 respectively. His research interests include networked and embedded control systems, industrial informatics, and power electronics.

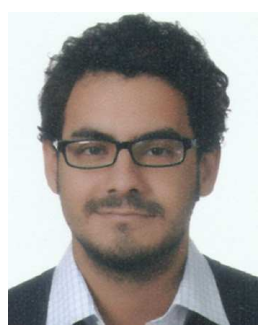

Juan Rey was born in Bucaramanga, Colombia in 1989. He received the B.S. in electrical engineering from Universidad Industrial de Santander, Bucaramanga, Colombia, in 2012, and the Ph.D. degree in electronic engineering from the Department of Electronic Engineering, Technical University of Catalonia, Spain, in 2019. Since 2013, he has been with the Electrical, Electronic and Telecommunications Engineering School (E3T), Universidad Industrial de Santander, Bucaramanga Colombia, where he is currently an Assistant Professor. His research interest include power electronics and control for distributed generation and microgrids.

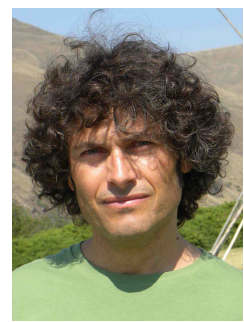

Jaume Miret (M'98) received the B.S. degree in telecommunications, M.S. degree in electronics, and Ph.D. degree in electronics from the Universitat Politecnica de Catalunya, Barcelona, Spain, in 1992, 1999, and 2005, respectively. From 1993 to 2011, he was an Assistant Professor in the Department of Electronic Engineering, Universitat Politecnica de Catalunya, Spain. Since 2011 he has been an Associate Professor in the Universitat Politecnica de Catalunya, where he teaches courses on digital design and circuit theory. His research interests include dc-to-ac converters, active power filters, and digital control. 


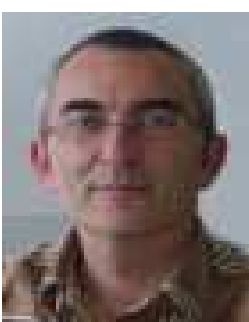

Miguel Castilla received the B.S., M.S. and Ph.D. degrees in telecommunication engineering from the Technical University of Catalonia, Barcelona, Spain, in 1988, 1995, and 1998, respectively. Since 2002, he has been an Associate Professor in the Department of Electronic Engineering, Technical University of Catalonia, where he teaches courses on analog circuits and power electronics. His research interests are in the areas of power electronics, nonlinear control, and renewable energy systems. 